\title{
VARIACIONES DEL FRACASO ESCOLAR
}

\section{VARIATIONS OF SCHOOL FAILURE}

Fecha de recepción: 10/4/19 Fecha de aceptación: 14/4/19

Resumen: El artículo se propone analizar el fracaso escolar desde la perspectiva del psicoanálisis. La inhibición interrogada a partir de la variable sujeto, en función de la relación con el inconsciente y el goce. Variaciones. La cuantificación del síntoma rechaza la noción de sujeto.

Palabras clave: Fracaso escolar - Inhibición -Variaciones

El debate sobre la calidad de la educación pública en nuestro país suele reinstalarse con frecuencia en el ámbito de los medios de comunicación y las redes sociales. Infructuoso, empujado por juicios de valor, perece con la misma rapidez que irrumpe, sin arrojar demasiadas consecuencias.

Entre tanto ruido, algunas opiniones. Frente al estado actual de la época en el que impera la hiperconectividad, Carlos Skliar 1, investigador especializado en educación, plantea que hoy un sujeto que aprende, un sujeto exitoso, es aquel que se híper adapta al mundo tal como se lo presentan. En ese sentido, educar es aprender a ganarse la vida, salir al mercado. Se trata de colocarse ante un desafío personal en el que el éxito depende del esfuerzo propio, de la auto capacitación o auto realización en un contrato privado.

Los proyectos estatales que se inician, a fines del siglo XIX, con los primeros vientos de la obligatoriedad escolar, han tomado una vertiente cada vez más tecnificada. El saber entra en la necesaria estandarización que consiga una transmisión idéntica, para todos, sin diferencia. La programa-

\section{CHRISTIAN MARTÍN}

Psicoanalista practicante en la ciudad de La Plata. Asociado a la Escuela de la Orientación Lacaniana (EOL) Sección La Plata. Se desempeña en el Servicio de Salud Mental del Hospital Zonal General de Agudos "Dr. Ricardo Gutiérrez" de La Plata. Autor de diferentes artículos en revistas especializadas.

Abstract: The article is proposed to analyse the School failure from the perspective of psychoanalysis. Intellectual inhibition questiones from the subjectvariable, based on its relationship with the unconscious and enjoyment. Variations. The quantification of the symptom rejects the notion of subject.

Key words: School failure - Inhibition - Variations

ción se vuelve exterior a la escuela, la deciden los técnicos en los Ministerios de Educación y Economía, que ejecutan de la misma manera. Vamos hacia una escuela sin maestros. 2

El fracaso escolar es una patología que gana un enorme terreno a partir de los cambios en las sociedades globalizadas del presente, en los que se inscriben los proyectos escolares. A aquellos sujetos que no están en condiciones de seguir el programa, de eso se trata después de todo, se les plantea una situación que pone en perspectiva un problema más vasto: la disolución de los lazos sociales.

El reflejo de época ante el fracaso escolar es plantearse el problema de la insuficiencia de las capacidades intelectuales, que suponen una deficiencia constitucional.3 El paso de esta demanda por las pruebas psicométricas, test de inteligencia, que miden la distancia del sujeto respecto de la media de los rendimientos de su edad, suelen reforzar la intuición de partida.

El diagnóstico se convierte en asunto de estadística, deshaciéndose de la noción de sujeto, se pasa de la cualidad a la cantidad. El síntoma es des- 
provisto de la opacidad del goce y de la lógica que encierra. 4 Como consecuencia de la desorientación que conlleva este deslizamiento, se prescriben dispositivos de enseñanza paralela, más o menos marginalizada del grueso de la matrícula, de la que muchas veces es difícil salir.

En la mayor parte de los casos, las llamadas funciones instrumentales se ubican en primer plano, se extrapolan abusivamente como una entidad aparte. El síntoma se erige como estructura, en lugar de permanecer ligado a la problemática más general del sujeto. 5 Esto abre una marcada divisoria de aguas entre la concepción psicologizante de la debilidad mental y la perspectiva del psicoanálisis.

\section{LA PERSPECTIVA PSICOANALÍTICA}

Me ha interesado el riguroso trabajo que realiza Anny Cordié, en su libro Los retrasados no existen. Psicoanálisis de niños con fracasos escolares.6 Allí la autora parte de la idea de abordar tanto la inteligencia como la debilidad mental a través del conjunto de operaciones que presiden el nacimiento del sujeto.

Cómo determinar qué es la inteligencia si no interrogamos de más cerca su instrumento, el lenguaje, constitutivo a su vez de la estructura misma del sujeto.7 Lacan lo presenta causado por dos operaciones, la alienación y la separación, la primera por vía significante, la otra, por la del objeto.

Si bien la inteligencia depende de la manera en que el sujeto organiza la lengua, también del acceso que tenga al saber sobre la lengua, ese saber que no se sabe. La infiltración del registro inconsciente en el orden del discurso no es otra cosa que lo que Lacan llama "leer entre líneas", entender más allá de las palabras. 8

En el débil mental está comprometida la movilidad del significante. Lacan da a este fenómeno de detención el nombre de holofrase, identificándola con la solidificación de una dupla de significantes, S1 S2, donde se trata de la suspensión de la función del significante como tal, la ausencia de intervalo, que lo hace no dialectizable. 9

\section{LA PULSIÓN EN LAS OPERACIONES COG- NITIVAS}

¿En qué consiste la articulación entre las operaciones intelectuales con aquello que corresponde al goce, objeto $a$ ?

"El lazo entre estas dos operaciones de causalidad del sujeto, la alienación (inconsciente freudiano) y la separación (el ello freudiano), plantea el profundo problema de la imbricación de los fenómenos lingüísticos y el goce; esto es lo que nos interesa en alto grado cuando intentamos precisar la parte de lo pulsional en las operaciones intelectuales y, por este mismo camino, el mecanismo inhibidor." 10

En la inhibición, el sujeto revela algo de su verdad a través de un no que es del orden del rechazo, es un acto: la suspensión del pensamiento es un acto del mismo tipo que la suspensión del hacer (anorexia, parálisis). Si lo comparamos con el no de la negación, que es una revelación del inconsciente encerrado en la cadena significante, la inhibición es un acto que se ubica más bien del lado del objeto.11

Un niño a punto de concluir el jardín de infantes, 12 presentaba una anorexia y una inhibición de la palabra. Encerrado en la pulsión oral de su madre, objeto portador de una angustia masiva, hablaba de un modo que sólo ella podía entender. Lo que la inquietaba, sin embargo, no era tanto un retardo en el lenguaje, como un rechazo alimenticio masivo que la sumía en una profunda angustia. El nacimiento del niño había reavivado acontecimientos muy dolorosos para ella. En un embarazo anterior presentó una grave anorexia y vómitos incontenibles que provocaron una desnutrición con tratamiento hospitalario, estado que puso en peligro la vida de ambos. El objeto oral era de una naturaleza mortífera, por razones que no se llegan a aclarar.

Al inicio de la cura, el niño no hablaba, pero significaba lo que debía hacerse, la analista modelaba personajes que para el niño resultan ser un perro. Comienza él a fabricarle un chorizo de pasta de modelar que fija al cuello del perro, luego el otro extremo a un árbol. Pronuncia la palabra "correa". Pasan muchas cosas alrededor de la relación amo-perro: lo convirtió en un animal que devoraba arvejas, que mordía las pantorrillas de la gente, en un lobo que devoraba niños.13

"Correa" (laisse) era la palabra que pronunciaba el padre en las comidas cuando la madre lo obligaba a comer. "Deja (laisse) tranquilo al niño" La correa representaba al mismo tiempo la ligazón peligrosa, pero necesaria, con la madre y la interdicción del padre.14

Se asiste a una inversión de la pulsión: morder, comer, en lugar de ser él mismo devorado. Luego se libera la palabra. Se protegía como podía contra esta angustia de muerte que retornaba bajo la 
forma: “come, no te mueras". Había construido un fantasma que podemos enunciar en estos términos: "dejar al niño perro con su correa". "El objeto oral está allí escondido en la animalidad del perro, y en la relación de devoración amo-perro. La cadena significante está allí con el equívoco del significante "laisse" que representa al mismo tiempo el lazo y la ruptura." 15

El interés de esta viñeta se desprende de la posibilidad de interrogar la inhibición desde la perspectiva de la clínica psicoanalítica, en función de la relación del sujeto con el inconsciente y con el goce, en tanto se opone a la perspectiva de la cuantificación de las funciones instrumentales, como hemos visto.

El niño logra concretar esta separación de su madre y del objeto oral a través de puestas en escena cada vez más elaboradas.16 El equívoco le permite desprenderse del objeto materno al que estaba identificado y perder su carácter angustiante. A su vez, produce una vivificación en su cuerpo al que aluden las sesiones posteriores a esa incidencia, el niño entraba corriendo al consultorio a inventar nuevas historias del perro, con las que se revolcaba de risa. El objeto ha perdido su carácter de puro real, se disolvió en el aparato del lenguaje conservando su potencia de goce.17 Luego será el tiempo de abandonar el tratamiento, había pasado a la escuela, a apasionarse por otras cosas.

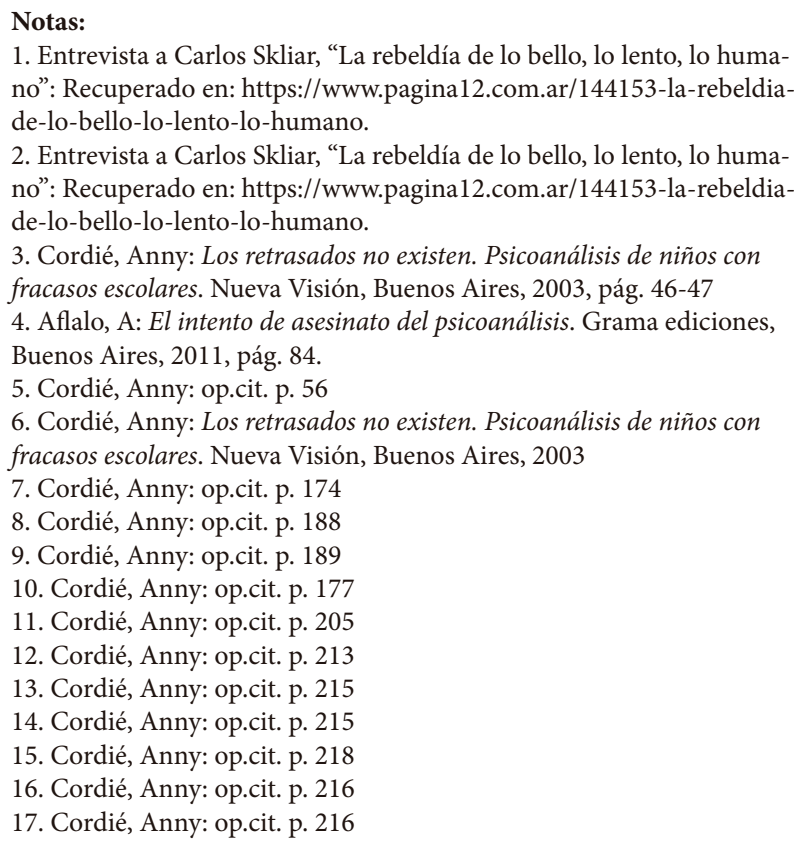

1. Entrevista a Carlos Skliar, "La rebeldía de lo bello, lo lento, lo humano": Recuperado en: https://www.pagina12.com.ar/144153-la-rebeldiade-lo-bello-lo-lento-lo-humano.

2. Entrevista a Carlos Skliar, "La rebeldía de lo bello, lo lento, lo humano": Recuperado en: https://www.pagina12.com.ar/144153-la-rebeldiade-lo-bello-lo-lento-lo-humano.

3. Cordié, Anny: Los retrasados no existen. Psicoanálisis de niños con fracasos escolares. Nueva Visión, Buenos Aires, 2003, pág. 46-47

4. Aflalo, A: El intento de asesinato del psicoanálisis. Grama ediciones, Buenos Aires, 2011, pág. 84.

5. Cordié, Anny: op.cit. p. 56

6. Cordié, Anny: Los retrasados no existen. Psicoanálisis de niños con fracasos escolares. Nueva Visión, Buenos Aires, 2003

7. Cordié, Anny: op.cit. p. 174

8. Cordié, Anny: op.cit. p. 188

9. Cordié, Anny: op.cit. p. 189

10. Cordié, Anny: op.cit. p. 177

11. Cordié, Anny: op.cit. p. 205

12. Cordié, Anny: op.cit. p. 213

13. Cordié, Anny: op.cit. p. 215

14. Cordié, Anny: op.cit. p. 215

15. Cordié, Anny: op.cit. p. 218

16. Cordié, Anny: op.cit. p. 216

17. Cordié, Anny: op.cit. p. 216 